Mots. Les langages du politique

$87 \mid 2008$

Chrononymes. La politisation du temps

\title{
Paul Bacot, Sylvianne Rémi-Giraud éd., Mots de l'espace et conflictualité sociale
}

Christian Le Bart

\section{(2) OpenEdition \\ Journals}

Édition électronique

URL : https://journals.openedition.org/mots/12902

DOI : $10.4000 /$ mots. 12902

ISSN : 1960-6001

Éditeur

ENS Éditions

Édition imprimée

Date de publication : 21 juillet 2008

Pagination : 131-133

ISBN : 978-2-271-06685-5

ISSN : 0243-6450

Référence électronique

Christian Le Bart, "Paul Bacot, Sylvianne Rémi-Giraud éd., Mots de l'espace et conflictualité sociale », Mots. Les langages du politique [En ligne], 87 | 2008, mis en ligne le 21 juillet 2010, consulté le 24 avril 2022. URL : http://journals.openedition.org/mots/12902 ; DOl : https://doi.org/10.4000/mots. 12902 


\section{Mots de l'espace et conflictualité sociale}

Paul Bacot, Sylvianne Rémi-Giraud éd.

2007, L'Harmattan (Langue \& Parole), 364 p.

Ce ne sont pas moins de trente-et-une contributions que Paul Bacotet Sylvianne Rémi-Giraud ont rassemblées dans l'ouvrage Mots de l'espace et conflictualité sociale. Issu d'un colloque tenu à Lyon en octobre 2001, ce travail collectif a fait le choix d'un balayage très large du thème de la spatialité en politique. La recherche explore, via des références disciplinaires très éclatées, et au moyen de méthodologies diverses, des objets eux-mêmes multiples, depuis les œuvres de Cioran jusqu'à la chanson protestataire nord-américaine, de l'anarchisme argentin au fascisme italien, du mythe de l'Atlantide au Monde diplomatique... La politique au sens traditionnel du terme est bien présente, avec ses professionnels, ses discours, ses partis, ses élections, son actualité, mais certains contributeurs débordent ce champ social pour s'intéresser à la poésie, à la chanson, aux gens ordinaires... Les coordinateurs de l'ouvrage ont d'ailleurs pris garde de titrer sur la « conflictualité sociale» et non sur « la politique » stricto sensu. Ils n'ont pas non plus restreint le champ d'analyse à la France d'aujourd'hui. Le lecteur voyage dans le temps et dans l'espace. Ils ne se sont pas davantage enfermés dans une définition stricte du discours et des mots. L'image et le geste ont aussi leur place en tant que productions symboliques pour autant qu'ils mobilisent la spatialité.

La problématique d'ensemble de l'ouvrage est simple à énoncer. En quoi l'espace, la spatialité, constituent-ils des ressources symboliques pour dire la conflictualité sociale? Le lecteur abordera sans doute l'ouvrage avec toute une série d'attentes concernant les figures les plus convenues : ainsi les clivages droite/gauche, proche/lointain, haut/bas... De fait, plusieurs des contributeurs s'efforcent d'analyser la prégnance de ces schémas binaires pour non seulement exprimer mais aussi plus généralement pour appréhender les choses sociales. Dans la lignée des recherches de Lakoff et Johnson (abondamment cités), les auteurs confirment que la spatialité n'est pas une façon parmi d'autres de dire le monde. Elle est, au niveau cognitif et donc en amont de la langue, la grille de lecture la plus ordinaire (la plus universelle?) qui soit.

La première partie de l'ouvrage, la plus dense, analyse les métaphores spatiales. Droite, gauche, centre, milieu... ont trouvé leur place dans le vocabulaire politique ordinaire. L'en-haut est toujours le lieu du pouvoir et de la légitimité. Les dominés ne peuvent subvertir l'ordre des mots et des choses qu'en renversant ces symboliques : la chanson protestataire nord-américaine invite à se redresser, à se relever (mouvement ascensionnel) ; les anarchistes argentins inversent la hiérarchie entre civilisation et barbarie. L'en-haut est aussi le lieu de l'excellence et de l'idéal, même si des tentatives peuvent être menées pour subvertir cet ordonnancement symbolique. Ainsi de la France 
d'en bas valorisée par Jean-Pierre Raffarin pourtant Premier Ministre. Basculement conjoncturel des symboliques politiques qui en dit long sur la crise des grandeurs politiques? La spatialité symbolique n'est en tout cas pas la géométrie : elle assimile le centre au sommet. La politique étant l'activité de domination par excellence, il n'est finalement pas surprenant que le registre de la verticalité s'y déploie à l'infini. Face à la récurrence et à la banalité de ces métaphores, les auteurs expriment la crainte d'être noyés sous le matériau. Ils ne peuvent que constater, avec Hugues Constantin de Chanay (p. 91), que «la notion apparemment innocente de métaphore spatiale cache en réalité des problèmes redoutables». La spatialité peut aussi être horizontale quand il s'agit pour un mouvement syndical d'aller de l'avant, de faire face, de se doter d'un programme ou d'un projet. L'analyse du discours cégétiste révèle ainsi une évolution : «L'adversaire n'est plus en haut; il est devant » (Pierre Lafon et Maurice Tournier, p. 165)

La seconde partie s'intéresse à l'exercice faussement innocent de désignation des lieux, dont on sait qu'il est une forme de pouvoir symbolique particulièrement importante. La violence symbolique des institutions s'affirme d'abord en effet à travers le pouvoir de nommer. Les termes ici recensés sont nombreux : quartier, orient/occident, nord/sud, est/ouest... Importe moins l'étymologie que l'usage qui est fait de ces termes. Comment les habitants disent-ils le quartier, avant que celui-ci ne soit institutionnalisé (par la loi Vaillant instaurant en 2002 les conseils de quartiers) ? La carte mentale chère aux géographes s'objective dans des désignations et des caractérisations utilisées pour dire les lieux de vie. Un terme apparemment aussi banal que rue cache un ensemble de représentations et de vision du monde urbain. Les mots qui désignent un lieu, qu'il s'agisse de l'Algérie ou de la Moldavie, donnent toujours à voir un point de vue sur celui-ci. Ils font toujours plus que situer sur une carte. Ils servent parfois à structurer une pensée, à condenser une représentation. Ainsi de l'opposition nord/sud chez les Verts ou chez les intellectuels latino-américains, dont le sens dépasse de très loin la géographie et même la géopolitique. Au fil des usages et des appropriations, les mots gagnent en densité. Le mot Sud, pour les militants du syndicat du même nom, s'est enrichi au fil du temps d'un imaginaire qui colle à la réalité du mouvement et à l'identité des militants en question. Il est désormais pour eux synonyme de solidarité, d'ouverture, de révolte des dominés, alors même qu'il a été initialement choisi un peu par hasard. «Si on s'était appelé Ouest, note malicieusement un militant interrogé par Hélène Pernot (p. 264), on aurait certainement pu, avec un peu de mauvaise foi, bricoler des rapprochements. »

De Pascal à Cioran, de la gestuelle de Lionel Jospin à l'activité onirique explorée par les psychologues, l'espace est partout. Peut-on penser le monde sans le spatialiser? Reste toutefois une interrogation, que les contributeurs ne font qu'esquisser : si on prend au sérieux les hypothèses socio- 
historiques diagnostiquant la déterritorialisation des pratiques sociales, peut-on diagnostiquer un déclin parallèle des imaginaires spatialisés? Les NTIC permettent, parait-il, de s'affranchir de l'espace. Mais peut-on se libérer des mots de l'espace?

Christian Le Bart

Université de Rennes 2, IEP, CRAPE (CNRS)

christian.lebart@uhb.fr 